\title{
Taking the Pulse of POCUS: The State of Point-of-Care Ultrasound at a Pediatric Tertiary Care Hospital
}

\author{
Peter Gutierrez, MD ${ }^{1,2}$; Tal Berkowitz, MD ${ }^{1,2}$; Lekha Shah, MD ${ }^{1,2}$; Stephanie G. Cohen, MD ${ }^{1,2}$ \\ (1) Emory University School of Medicine, Atlanta, GA \\ (2) Children's Healthcare of Atlanta, Atlanta, GA
}

\begin{abstract}
We aim to quantify and categorize point-of-care ultrasound (POCUS) usage by pediatric practitioners and trainees at our tertiary care center, and assess the degree of interest from pediatric residents, fellows, and program leaders for integrating POCUS into their training. Data was collected via online survey, evaluating the current use of POCUS in clinical decision making, desire for further formal training, and opinions on the importance of POCUS to future clinical practice. In total, 14 program directors/assistant program directors (PD/APDs) representing 10 of 15 training programs, 30 of 95 fellows representing 9 of 15 fellowships, and 32 of 82 residents responded. From PD/APDs, only 2 of the programs reported active use POCUS for clinical decision making, but 13 of the fellows and 9 residents reported doing so. In regard to desire for a formal POCUS program, $30.8 \%$ of PD/APDs, $43.8 \%$ of fellows without current curricula, and $87.5 \%$ of residents were interested in participating in such a program. When considering specialty, some nonacute care-based PD/APDs and fellows at our institution felt that POCUS was important to future practice. Pediatric subspecialty PD/APDs and their fellows had divergent outlooks on the importance of POCUS in future practice. Finally, an overwhelming majority of residents at our institution expressed a desire to learn, and half believing it will be important to future practice. Based on the degree of interest, medicolegal considerations, and trajectory of patient care, pediatric residency and fellowship programs should strongly consider integrating POCUS education into their curricula.
\end{abstract}

\section{Background}

Point-of-care ultrasound (POCUS), ultrasound both performed and interpreted by a clinician at the bedside and used to answer immediate questions or to perform procedures, is becoming an integral part of daily practice in many areas of medicine. Most published curricula exist in adult-focused specialties, including emergency medicine (1-3), internal/family medicine [4-7], critical care [8], general surgery [9], anesthesiology [10], and nephrology [11]. There are few similar publications in pediatric specialties, with pediatric emergency medicine and critical care being notable exceptions [12-15]. While POCUS is most consistently used in the acute care setting, it also has applications in the ambulatory and inpatient settings [16].

To our knowledge, there are no published reports of the degree of POCUS use in pediatric subspecialties. Currently, there are multiple pediatric subspecialties that have board content specifications that involve ultrasound, but the majority involve only knowing its indications or limitations (adolescent medicine, child abuse pediatrics, neonatology), interpretation of scans performed by technicians or radiologists (gastroenterology, plastic surgery), or have very limited applications (cardiology). Other subspecialties express only an awareness of the modality (endocrinology, neurology/epileptology, neurosurgery). Pediatric emergency medicine (EM) is unique in that its board content specifications explicitly mentions POCUS [17-27]. In spite of this, multiple specialties at our institution report the use of POCUS in clinical decision-making, which prompted our inquiry. The primary purpose of this study is to quantify and categorize the use of POCUS by pediatric subspecialists across our large tertiary care academic pediatric hospital system. Secondary aims of this study were to assess the degree of interest in formal POCUS training and perceived importance to future clinical practice by pediatric trainees and their program leaders.

\section{Methods}

Data from this study was collected via an online survey. One survey type was sent to the program directors and associate program directors (PDs/APDs) for the pediatric residency and pediatric fellowships at our institution. $A$ separate, but similar, survey sent to the general pediatric residents and subspecialty fellows in training at our institution at the time of administration. Surveys listed demographics, training level, questions about current practice and future training interest in POCUS, and attitudes about the importance of POCUS in future clinical practice. Surveys were created in REDCAP and 
disseminated via email. Results were de-identified and underwent descriptive statistical analysis upon completion of the study period. Current PD/APDs of general pediatrics or a pediatric subspecialty, general pediatric residents, or pediatric subspecialty fellows were included. There were no exclusion criteria. Data was compiled on secure SharePoint and REDCAP sites. Statistical analyses were performed using Microsoft Excel (Microsoft Excel for Mac 2019, Microsoft Corporation, Version 16.34), which included calculating percentages. This study was granted exemption from our institutional review board.

\section{Results}

In total, 14 PDs/APDs responded to the survey, representing 10 of the 15 pediatric fellowship programs available at our institution. Respondents included representatives from endocrinology, cardiology, gastroenterology (GI), nephrology, allergy/immunology, hematology/oncology, rheumatology, neurology, neonatology, and critical care medicine (CCM). Only two of the respondents, a rheumatologist and a cardiologist, indicated that they personally perform point-of-care ultrasound scans for medical decision-making. The rheumatologist reporting using point-of-care (POC) musculoskeletal imaging, and the cardiologist reported using POC noncardiac thoracic imaging. Regarding the importance of POCUS in future practice of their specialty, four respondents indicated it was "important" and the remaining ten were either neutral or reported it was not important. Currently, only one program (CCM) reported having a current POCUS curriculum for their fellows. Of note, the program director for EM did not respond, but that specialty is known to have a formal curriculum for its fellows. Four of 13 respondents without a POCUS program, cardiology, nephrology, endocrinology, and neonatology, reported a desire to create a POCUS course for their fellows (Table 1).

Thirty out of 95 fellows representing 9 of 15 total fellowships responded to the survey. Regarding types of scans being performed for clinical decision making, thirteen respondents reported using POCUS clinically to some degree while 17 reported not using it at all. All applications except airway, thyroid, abdomen, and male genitourinary (GU) were reported as currently used. When CCM and EM fellows were removed, only cardiac, aorta, renal/bladder, MSK, soft tissue, and thoracic modalities were reported. Remaining reports were from cardiology fellows, except for one MSK respondent from an undeclared specialty. When asked what applications fellows wanted to learn, respondents from nine different specialties listed at least one application they felt would be beneficial to their practice. With regards to importance of POCUS to the future of their specialty, 16 of 30 responded "important" or "very important", while 14 responded neutral or not important. Currently, only critical care medicine, emergency medicine, and cardiology respondents reported having a POCUS curriculum. Of note, there were two respondents from cardiology, one of whom reported that their program had a formal POCUS curriculum, while other reported that there was not one. Of the 18 non-EM/CCM fellow respondents that are known to not have a POCUS curriculum, eight would like to start a program, including those from endocrinology, $\mathrm{GI}$, hospitalist medicine, neonatology, two that did not report their training program, and the other respondent from cardiology (Table 2).

The survey administered to residents included 32 completed surveys from a possible 76 categorical general pediatric (GP) residents and 6 General Pediatric/ Neurology (GP/N) residents, of which 17 came from GP, 3 from GP/N, and 12 unreported. Despite no formal training program, nine residents did report currently using a variety of POCUS modalities, most commonly soft tissue. When asked about which POCUS modalities they would like to learn, all modalities were mentioned by at least one resident, but the most common responses were extended focused assessment with sonography for trauma (eFAST), cardiac, MSK, soft tissue, and abdomen. Half of the residents reported POCUS is either "important" or "very important" to their future learning, while the other half felt it is either "not important" or are "neutral." (Table 3).

\section{Discussion}

Within our institution there is currently formal POCUS training limited to two specialties, EM and CCM, with some formal teaching in cardiology in addition to their echocardiography training, but not an official POCUS curriculum.

Outside of EM, CCM, cardiology, and rheumatology, faculty did not have experience with POCUS, and most did not feel it is important for their fellows' education. However, there is indeed desire from a few subspecialists at our institution to create a formal curriculum for their fellows.

On the other hand, about half of subspecialty trainees reported that POCUS is an important part of their future education with fellows desiring a broader array of modalities to learn compared to residents. While currently the majority of POCUS is being performed by fellows in $\mathrm{EM}, \mathrm{CCM}$, and cardiology, fellows from a number of other specialties expressed a desire to learn at least one modality of POCUS, typically one specifically related to their field, for example a nephrology fellow desiring to learn renal/bladder US, and an endocrine fellow desiring to learn thyroid US. There appeared to be a considerable 
82 | POCUS J | Nov 2021 vol. 06 iss. 02

Table 1. Responses from PD/APDs to POCUS Survey

\begin{tabular}{|c|c|c|c|}
\hline Question & Response Choice & Response No. (\%) & Specialty \\
\hline Number of respondents & & 14 & \\
\hline Program Directors & & 7 of $14(50 \%)$ & \\
\hline \multirow[t]{10}{*}{ Program represented } & Allergy/immunology (A/l) & 1 & \\
\hline & Cardiology & 2 & \\
\hline & Critical Care Medicine (CCM) & 1 & \\
\hline & Endocrinology & 2 & \\
\hline & Gastroenterology (GI) & 1 & \\
\hline & Hematology/Oncology $(\mathrm{H} / \mathrm{O})$ & 2 & \\
\hline & Neonatology & 1 & \\
\hline & Nephrology & 2 & \\
\hline & Neurology & 1 & \\
\hline & Rheumatology & 1 & \\
\hline \multirow[t]{4}{*}{ Years in practice } & Less than 5 years & 3 of $14(21.4 \%)$ & \\
\hline & 5 to 10 years & $5(35.7 \%)$ & \\
\hline & 10 to 15 hours & $2(14.3 \%)$ & \\
\hline & more than 15 years & $4(28.6 \%)$ & \\
\hline \multirow[t]{4}{*}{ Years in PD/APD role } & Less than 5 years & 9 of $14(64.3 \%)$ & \\
\hline & 5 to 10 years & $3(21.4 \%)$ & \\
\hline & 10 to 15 hours & $2(14.3 \%)$ & \\
\hline & more than 15 years & $0(0 \%)$ & \\
\hline $\begin{array}{l}\text { Currently use POCUS in clinical } \\
\text { practice }\end{array}$ & & 2 of $14(14.3 \%)$ & Cardiology, Rheumatology \\
\hline \multirow[t]{3}{*}{ Modality used in current practice } & Thoracic & 1 of $14(7.1 \%)$ & Cardiology \\
\hline & Musculoskeletal & $2(14.3 \%)$ & Rheumatology \\
\hline & All others & 0 & \\
\hline $\begin{array}{l}\text { POCUS modalities beneficial for } \\
\text { present/future practice }\end{array}$ & All modalities & 0 of $14(0 \%)$ & \\
\hline \multirow[t]{5}{*}{$\begin{array}{l}\text { Anticipating importance of POCUS in } \\
\text { future practice }\end{array}$} & Very Important & 0 of $14(0 \%)$ & \\
\hline & Important & $4(28.6 \%)$ & $\begin{array}{l}\text { Cardiology, Endocrinology, } \\
\text { Nephrology, Rheumatology }\end{array}$ \\
\hline & Neutral & $5(35.7 \%)$ & $\begin{array}{l}\text { A/l, Cardiology, CCM, H/O, } \\
\text { Neonatology }\end{array}$ \\
\hline & Not Important & $3(21.4 \%)$ & $\begin{array}{l}\text { Endocrinology, Nephrology, } \\
\text { Neurology }\end{array}$ \\
\hline & Not Important at all & $2(14.3 \%)$ & $\mathrm{GI}, \mathrm{H} / \mathrm{O}$ \\
\hline $\begin{array}{l}\text { Currently have a POCUS training } \\
\text { curriculum }\end{array}$ & & 1 of $14(7.1 \%)$ & $\mathrm{CCM}$ \\
\hline $\begin{array}{l}\text { Planning on creating a POCUS } \\
\text { training curriculum }\end{array}$ & & 0 of $14(0 \%)$ & \\
\hline $\begin{array}{l}\text { Interest in having trainees participate } \\
\text { in POCUS curriculum } \\
{ }^{*} \text { Note: Denominator excludes CCM, } \\
\text { which already had a curriculum. }\end{array}$ & & 4 of $13(30.8 \%)$ & $\begin{array}{l}\text { Cardiology, Nephrology, } \\
\text { Endocrinology, Neonatology }\end{array}$ \\
\hline $\begin{array}{l}\text { POCUS quality assurance program in } \\
\text { place }\end{array}$ & & 0 of $14(0 \%)$ & \\
\hline
\end{tabular}


Table 2. Responses from subspecialty fellows to POCUS survey. (Continues on next page)

\begin{tabular}{|c|c|c|c|}
\hline Question & Selection & Response No. (\%) & Subspecialty \\
\hline Number of respondents & & 30 of $95(31.6 \%)$ & \\
\hline \multirow[t]{10}{*}{ Programs represented } & Cardiology & 2 & \\
\hline & Critical Care Medicine (CCM) & 5 & \\
\hline & Emergency Medicine (EM) & 7 & \\
\hline & Endocrinology & 4 & \\
\hline & Gastroenterology $(\mathrm{Gl})$ & 2 & \\
\hline & Hematology/Oncology $(\mathrm{H} / \mathrm{O})$ & 3 & \\
\hline & Hospitalist Medicine (HM) & 1 & \\
\hline & Neonatology & 2 & \\
\hline & Nephrology & 1 & \\
\hline & Unreported & 3 & \\
\hline \multirow[t]{4}{*}{ Post-graduate year } & 4 & 7 of $30(23.3 \%)$ & \\
\hline & 5 & $13(43.3 \%)$ & \\
\hline & 6 & $9(30.0 \%)$ & \\
\hline & 7 & $1(3.3 \%)$ & \\
\hline $\begin{array}{l}\text { Currently use POCUS in } \\
\text { clinical practice }\end{array}$ & & 13 of $30(40.6 \%)$ & $\begin{array}{l}\text { Cardiology, CCM, EM, } \\
\text { Unreported }\end{array}$ \\
\hline \multirow[t]{13}{*}{$\begin{array}{l}\text { Modality used in current } \\
\text { practice }\end{array}$} & Aorta & 2 of $30(6.7 \%)$ & Cardiology, EM \\
\hline & Biliary & $1(3.3 \%)$ & EM \\
\hline & eFAST & $7(23.3 \%)$ & EM \\
\hline & Focused Cardiac & $5(16.7 \%)$ & Cardiology, CCM, EM \\
\hline & Musculoskeletal & $5(16.7 \%)$ & EM, Unreported \\
\hline & Obstetric & $2(6.7 \%)$ & EM \\
\hline & Ocular & $3(10.0 \%)$ & EM \\
\hline & Renal/Bladder & $5(16.7 \%)$ & Cardiology, CCM, EM \\
\hline & Soft tissue & $9(30.0 \%)$ & Cardiology, CCM, EM \\
\hline & Thoracic & $3(10.0 \%)$ & Cardiology, CCM, EM \\
\hline & Vascular/DVT & $3(10.0 \%)$ & CCM, EM \\
\hline & Other Modalities & 0 & \\
\hline & Do not perform POCUS & $17(56.7 \%)$ & \\
\hline $\begin{array}{l}\text { POCUS modalities fellows } \\
\text { want to learn }\end{array}$ & Abdomen & 11 of $30(36.7 \%)$ & CCM, EM, GI, HM, Unreported \\
\hline \multirow{6}{*}{$\begin{array}{l}\text { *Note: Denominator is } \\
\text { number of fellows that } \\
\text { don't already know the } \\
\text { modality* }\end{array}$} & Airway & 8 of $30(26.7 \%)$ & $\begin{array}{l}\text { Cardiology, CCM, EM, } \\
\text { Neonatology, Unreported }\end{array}$ \\
\hline & Aorta & 3 of $28(10.7 \%)$ & CCM, EM \\
\hline & Biliary & 2 of $29(6.9 \%)$ & EM \\
\hline & eFAST & 6 of $23(26.1 \%)$ & Cardiology, CCM, EM \\
\hline & Focused Cardiac & 9 of $25(36.0 \%)$ & $\begin{array}{l}\text { CCM, EM, Neonatology, } \\
\text { Unreported }\end{array}$ \\
\hline & Male Genitourinary & 3 of $30(10.0 \%)$ & EM, Endocrinology \\
\hline
\end{tabular}


Table 2 (con't). Responses from subspecialty fellows to POCUS survey.

\begin{tabular}{|c|c|c|c|}
\hline Question & Selection & Response No. (\%) & Subspecialty \\
\hline $\begin{array}{l}\text { POCUS modalities fellows } \\
\text { want to learn }\end{array}$ & Musculoskeletal & 4 of $25(16.0 \%)$ & EM, H/O \\
\hline \multirow{7}{*}{$\begin{array}{l}{ }^{*} \text { Note: Denominator is } \\
\text { number of fellows that don't } \\
\text { already know the modality* }\end{array}$} & Obstetric & 3 of $28(10.7 \%)$ & EM, Endocrinology \\
\hline & Ocular & 5 of $27(18.5 \%)$ & EM, Unreported \\
\hline & Renal/Bladder & 5 of $25(20.0 \%)$ & CCM, EM, Nephrology \\
\hline & Soft tissue & 4 of $21(19.0 \%)$ & $\mathrm{H} / \mathrm{O}, \mathrm{HM}$, Unreported \\
\hline & Thoracic & 6 of $27(22.2 \%)$ & CCM, EM, Neonatology \\
\hline & Thyroid & 4 of $30(13.3 \%)$ & Endocrinology \\
\hline & Vascular/DVT & 8 of $27(29.6 \%)$ & $\begin{array}{l}\mathrm{CCM}, \mathrm{EM}, \mathrm{H} / \mathrm{O} \text {, Neonatology, } \\
\text { Unreported }\end{array}$ \\
\hline \multirow{5}{*}{$\begin{array}{l}\text { Anticipating importance of } \\
\text { POCUS in future practice }\end{array}$} & Very Important & 8 of $30(26.7 \%)$ & CCM, EM, Unreported \\
\hline & Important & $8(26.7 \%)$ & $\begin{array}{l}\text { Cardiology, CCM, EM, } \\
\text { Endocrinology, HM, Unreported }\end{array}$ \\
\hline & Neutral & $7(23.3 \%)$ & $\begin{array}{l}\text { Cardiology, CCM, Endocrinology, } \\
\text { GI, H/O, Neonatology, } \\
\text { Unreported }\end{array}$ \\
\hline & Not Important & $4(17.4 \%)$ & $\begin{array}{l}\text { Endocrinology, GI, Neonatology, } \\
\text { Nephrology }\end{array}$ \\
\hline & Not Important at all & $3(10.0 \%)$ & Endocrinology, $\mathrm{GI}, \mathrm{H} / \mathrm{O}$ \\
\hline $\begin{array}{l}\text { Programs with a POCUS } \\
\text { training curriculum }\end{array}$ & Yes & 4 of $30(13.3 \%)$ & $\begin{array}{l}\text { Cardiology, CCM, EM, } \\
\text { Unreported }\end{array}$ \\
\hline $\begin{array}{l}\text { Interest in participating in } \\
\text { POCUS Curriculum }\end{array}$ & Yes & 7 of $16(43.8 \%)$ & $\begin{array}{l}\text { Endocrinology, GI, Neonatology, } \\
\text { Unreported }\end{array}$ \\
\hline $\begin{array}{l}\text { *Note: Denominator is } \\
\text { number of fellows from } \\
\text { programs that don't } \\
\text { already have a program* }\end{array}$ & & & \\
\hline
\end{tabular}

disconnect in the perceived future importance and current desire to learn POCUS between subspecialty PDs/APDs and their fellows. It is notable that there was significant overlap in the specialties reported for each cohort.

Among residents, there was little current practice, and it is unclear whether the current use is taking place under the guidance of trained practitioners such as in the Emergency Department or Intensive Care Unit. While approximately half of residents that responded indicated that POCUS is important to their future practice, almost all of them expressed desire to learn POCUS, with the most desired modalities being abdomen, soft tissue, and eFAST.

The data from out institution indicate that POCUS training for general pediatric and pediatric subspecialty trainees is believed to the important to future practice, and residency/fellowship programs should strongly consider integrating it into their training. First, aspects of clinical ultrasound are being incorporated into most subspecialty content specifications and require competency in POCUS in others. Second, if adult medical practice is a roadmap for the eventual direction of pediatric care, it is likely that POCUS will be further incorporated into the standard evaluation of pediatric patients. By having pediatric practitioners proactively adopt POCUS training, our pediatric patients would benefit from the same standard of care that adult patients receive. Third, with regards to future practice, CPT codes have already been established for reimbursement, making POCUS not only useful for patient care, but financially viable [28]. Lastly, a number of trainees reported already using POCUS without formal training, which makes institutions and providers vulnerable to potential medicolegal litigation should these scans be interpreted incorrectly and applied to patient care.

A major limitation of this study is the response rate to the survey, specifically from the trainees, totaling about $1 / 3$ of possible respondents. Another limitation is that this was performed at a single institution and may not reflect attitudes nationally across other pediatric centers. Also, 
Table 3. Responses from residents to POCUS survey.

\begin{tabular}{|c|c|c|}
\hline Question & Selection & Response No. (\%) \\
\hline Number of respondents & & 32 of $82(39.0 \%)$ \\
\hline \multirow[t]{3}{*}{ Programs represented } & General Pediatrics (GP) & 17 of $32(53.1 \%)$ \\
\hline & General Pediatrics/Neurology (GP/N) & $3(9.4 \%)$ \\
\hline & Unreported & $12(37.5 \%)$ \\
\hline \multirow[t]{4}{*}{ Post-graduate year } & 1 & 6 of $32(18.8 \%)$ \\
\hline & 2 & $14(43.8 \%)$ \\
\hline & 3 & $11(34.4 \%)$ \\
\hline & 4 or higher & $1(3.1 \%)$ \\
\hline \multirow[t]{3}{*}{ Currently use POCUS in clinical practice } & GP & 5 of $32(15.6 \%)$ \\
\hline & $\mathrm{GP} / \mathrm{N}$ & 0 \\
\hline & Unreported & $4(12.5 \%)$ \\
\hline \multirow[t]{6}{*}{ Modality used in current practice } & Abdominal & 2 of $32(6.3 \%)$ \\
\hline & Biliary & $1(3.1 \%)$ \\
\hline & eFAST & $2(6.3 \%)$ \\
\hline & Musculoskeletal & $1(3.1 \%)$ \\
\hline & Soft tissue & $6(18.8 \%)$ \\
\hline & Other Modalities & 0 \\
\hline $\begin{array}{l}\text { POCUS modalities beneficial for present/future } \\
\text { practice }\end{array}$ & Abdomen & 19 of $32(59.4 \%)$ \\
\hline \multirow[t]{14}{*}{$\begin{array}{l}\text { *Note: Denominator unchanged since residents } \\
\text { have no formal POCUS training* }\end{array}$} & Airway & $11(34.4 \%)$ \\
\hline & Aorta & $4(12.5 \%)$ \\
\hline & Biliary & $6(18.8 \%)$ \\
\hline & eFAST & $16(50.0 \%)$ \\
\hline & Focused Cardiac & $13(40.6)$ \\
\hline & Male Genitourinary & $7(21.9 \%)$ \\
\hline & Musculoskeletal & $14(43.8 \%)$ \\
\hline & Obstetric & $4(12.5 \%)$ \\
\hline & Ocular & $5(15.6 \%)$ \\
\hline & Renal/Bladder & $12(37.5 \%)$ \\
\hline & Soft tissue & $16(50.0 \%)$ \\
\hline & Thoracic & $7(21.9 \%)$ \\
\hline & Thyroid & $3(9.4 \%)$ \\
\hline & Vascular/DVT & $11(34.4 \%)$ \\
\hline \multirow[t]{5}{*}{$\begin{array}{l}\text { Anticipating importance of POCUS in future } \\
\text { practice }\end{array}$} & Very Important & 5 of $32(15.6 \%)$ \\
\hline & Important & $11(34.4 \%)$ \\
\hline & Neutral & $8(25.0 \%)$ \\
\hline & Not Important & $6(18.8 \%)$ \\
\hline & Not Important at all & $2(6.3 \%)$ \\
\hline Interest in participating in POCUS curriculum & Yes & 28 of $32(87.5 \%)$ \\
\hline
\end{tabular}

results of the study may be skewed by those willing to respond. For example, those who currently have ultrasound curricula and those who desire to learn POCUS may have been more likely to respond to the survey, as evidenced by the fact that PEM and PCCM were the two groups with the highest representation in the fellows' cohort. Finally, perceived ambiguity in the survey and inconsistency in respondents' answers offer some confounding, such as when one cardiology fellow reported that they had a POCUS curriculum, but the other did not.

\section{Conclusions}

While there is no distinct consensus between trainees and their program leaders regarding the importance of POCUS in pediatric general and subspecialty training, there is significant desire at our institution for education and incorporation of POCUS into training and clinical 
care. As POCUS is a relatively new field in pediatrics, it is not entirely surprising that outside of the specialties that have more traditionally used POCUS, namely EM, CCM, and cardiology, there is not significant use of POCUS in clinical decision-making. Additionally, it is not surprising that trainees who are earlier in their career are more likely than their faculty to desire formal training in POCUS be incorporated into their curricula. There is a clear limitation to this study in that the response rate was less than fifty percent, however the study still demonstrates substantial interest at our institution in learning and incorporating a new clinical skill in an area in which current clinical expertise amongst residents, fellows, and subspecialists is clearly lacking. Pediatric training programs should strongly consider integrating POCUS education into their current curricula for residents/fellows given the current trends in training requirements, future viability of POCUS beyond patient care, and possible medicolegal liability of scans being performed by untrained practitioners. While POCUS applications different among the various subspecialties, this study demonstrates that there is a need to incorporate POCUS education into training. Further studies are needed, including a survey of multiple institutions, to evaluate the generalizability of these findings. Other future studies/projects should focus on the creation of a POCUS curriculum with skills that are generalizable across subspecialties, as well as specialtyspecific applications.

\section{Conflict of Interest}

The authors have no conflicts of interest to disclose.

\section{References}

1. J.S. Boyd, C.M. LoPresti, M. Core, et al., Current use and training needs of point of care ultrasound in emergency departments: A national survey of VA hospitals, Am J Emerg Med. 2019;37:1794-1797. doi: 10.1016/j.ajem.2019.02.043.

2. American College of Emergency Physicians. Ultrasound Guidelines: Emergency, Point-of-Care and Clinical Ultrasound Guidelines in Medicine. Ann Emerg Med. 2017;69:e27-e54.

3. Wilson J, Lewiss R, Lum D. Education innovation: A four-week pointof-care ultrasound mini-fellowship for physicians in practice. Am J Emerg Med. 2018;36:155-156. doi: 10.1016/j.ajem.2017.07.029.

4. Anstey J, Jensen T, Afshar N. Point-of-care ultrasound needs assessment, curriculum design, and curriculum assessment in a large academic internal medicine residency program. South Med J, 2018;111:444-448. doi: 10.14423/SMJ.0000000000000831.

5. Bornemann P. Assessment of a novel point-of-care ultrasound curriculum's effect on competency measures in family medicine graduate medical education. J Ultrasound Med. 2017;36:1205-1211. doi: 10.7863/ultra.16.05002.

6. Galen B, Conigliaro R. The Montefiore 10: a pilot curriculum in pointof-care ultrasound for internal medicine residency training. J Grad Med Educ. 2018;10:110-111. doi: 10.4300/JGME-D-17-00683.1.

7. Ma I, Arishenkoff S, Wiseman J, et al. Internal Medicine Point-of-Care Ultrasound Curriculum: Consensus Recommendations from the Canadian Internal Medicine Ultrasound (CIMUS) Group. J Gen Intern
Med. 2017;32:1052-1057. doi: 10.1007/s11606-017-4071-5.

8. Watson et al. Point of care ultrasound training for internal medicine: a Canadian multi-centre learner needs assessment study. BMC Med Educ (2018) 18:217. doi: 10.1186/s12909-018-1326-8

9. Pustavoitau A, Blaivas M, Brown S, et al. Recommendations for Achieving and Maintaining Competence and Credentialing in Critical Care Ultrasound with Focused Cardiac Ultrasound and Advanced Critical Care Echocardiography. http://journals.Iww.com/ccmjournal/ Documents/Critical Care Ultrasound.pdf. Accessed 6 May 2019.

10. Beal E, Sigmond B, Safe-Silski L, Lahey S, Nguyen V, Bahner D. Point-of-care ultrasound in general surgery residency training. J Ultrasound Med. 2017;36:2577-2584. doi: 10.1002/jum.14298.

11. Mok D, Schwarz SKW, Rondi K. Point-of-care ultrasonography in Canadian anesthesiology residency programs: a national survey of program directors. Can J of Anaesth. 2017;64:1023-1036. doi:10.1007/ s12630-017-0935-8.

12. Niyyar V, O'Neill W. Point-of-care ultrasound in the practice of nephrology. Kidney Int. 2018;93:1052-1059. doi: 10.1016/ j.kint.2017.11.032

13. Marin JR, Zuckerbraun NS, Kahn JM. Use of Emergency Ultrasound in United States Pediatric Emergency Medicine Fellowship Programs in 2011. J Ultrasound Med. http://onlinelibrary. wiley.com/doi/10.7863/ jum.2012.31.9.1357/full; 2012. Accessed 6 May 2019.

14. Gold DL, Marin JR, Haritos D, et al. Pediatric Emergency Medicine Physicians' Use of Point $\square$ of $\square$ care Ultrasound and Barriers to Implementation: A Regional Pilot Study. AEM Education and Training. https://onlinelibrary.wiley.com/doi/abs/10.1002/aet2.10049; 2017. Accessed 6 May 2019.

15. Marin JR, Lewiss RE, American Academy of Pediatrics, Committee on Pediatric Emergency Medicine, Academy of Emergency Ultrasound, Pediatric Emergency Medicine Committee. Point-of-Care

Ultrasonography by Pediatric Emergency Medicine Physicians.

Pediatrics. https://pediatrics.aappublications.org/content/135/4/e1113; 2015. Accessed 6 May 2019.

16. Srinivasan S, Cornell TT. Bedside ultrasound in pediatric critical care: a review. Pediatric critical care medicine: a journal of the Society of Critical Care Medicine and the World Federation of Pediatric Intensive and Critical Care Societies. https://www.ncbi.nlm.nih.gov/pmc/ articles/PMC3315182/; 2011. Accessed 6 May 2019.

17. Hopkins A, Doniger S. Point-of-Care Ultrasound for the Pediatric Hospitalist's Practice. Hospital Pediatrics. 2019;9:707-718. DOI: 10.1542/hpeds.2018-0118.

18. American Board of Pediatrics. Content Outlines for Subspecialties. https://www.abp.org/content/content-outlines-subspecialties; 2020. Accessed 15 October 2020.

19. American Board of Allergy and Immunology. Item Classification List. https://www.abai.org/Outline.asp; 2015. Accessed 29 April 2019.

20. American Board of Anesthesiology. Pediatric Anesthesiology Examination. http://www.theaba.org/PDFs/Pediatrics-Anesthesiology/ PAContentOutline; 2019. Accessed 29 April 2019.

21. Congenital Cardiac Anesthesia Society. https://www.ccasociety.org/; 2020. Accessed 28 April 2020.

22. American Board of Plastic Surgery. Written Examination and Continuous Certification Program Content Outline. https:// www.abplasticsurgery.org/media/13991/ABPS-Content-Outline-finalApproved-5-18-18.pdf; 2018. Accessed 29 April 2019.

23. American Board of Psychiatry and Neurology. Certification Examination in Child Neurology. https://www.abpn.com/wp-content/ uploads/2017/01/2017 Child Neurology CERT Content Specifications .pdf; 2017. Accessed 28 February 2020.

24. American Board of Surgery. Hand Surgery: Content Outline for the Certifying and Recertifying Examinations. http://www.absurgery.org/xfer/ SOTH-CE-RECERT.pdf; 2009. Accessed 28 February 2020.

25. American Board of Neurological Surgery. American Board of Neurological Surgery Content Categories. https://abns.org/wp-content/ uploads/2018/03/Final-2016-ABNS-Content-Outline.pdf; 2016. Accessed 28 February 2020

26. American Board of Orthopedic Surgery. ABOS Part I Certification 
Examination Blueprint. https://www.abos.org/wp-content/ uploads/2019/01/abos blueprint part i.pdf; Accessed 28 February 2020.

27. American Board of Physical Medicine and Rehabilitation. Pediatric Rehabilitation Medicine Examination Outline. https://

abpmrprodstorage.file.core.windows.net/pdfs/prm/prm outline.pdf?

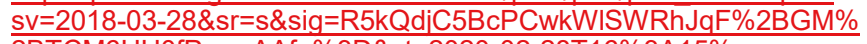
2BTCM6UH0fPcuwAAfg\%3D\&st=2020-02-28T16\%3A15\%

3 A02Z\&se $=2020-02-28 T 16 \% 3 A 30 \% 3 A 02 Z \& s p=r ;$ Accessed 28

February 2020.

28. The Society of Point of Care Ultrasound. "SPOCUS Reimbursement Statement." https://spocus.org/admin-resources/billing-statement/, Accessed 10/1/2020. 